\title{
ГЕНЕТИКА
}

GENETICS

\section{About the origin of the acrocentric part of non-acrocentric satellited chromosomes in humans}

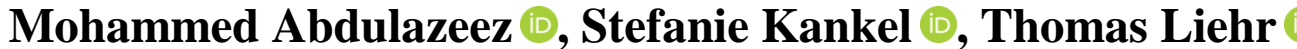 \\ Jena University Hospital, Friedrich Schiller University, Institute of Human Genetics, \\ Am Klinikum 1, D-07747 Jena, Germany \\ Corresponding author: Thomas Liehr(Thomas.Liehr@med.uni-jena.de)
}

\begin{abstract}
Background: Variants in size of the acrocentric short arms (acro-ps) are normally not reported and considered as chromosomal heteromorphisms (CHMs) without any influence on the carrier's phenotype. However, if acro-ps are translocated to ends of A-chromosomes (i.e. human chromosomes 1-22 and X or Y), those rearrangements are studied in more detail. The aim of the study: Here we characterized 11 healthy carriers of a non-acrocentric satellited chromosomes $\operatorname{der}(\mathrm{A}) \mathrm{t}(\mathrm{A} ; \mathrm{acro})(\mathrm{pter}$ or qter;p1?1.2) to determine the frequency of chromosome 15p and 22p in such rearrangements. Materials and methods: 11 carriers of one (10 cases) or two (1 case) $\operatorname{der}(\mathrm{A}) \mathrm{t}(\mathrm{A} ; \mathrm{acro})$ were identified during routine cytogenetic analyses. They were originally referred due to infertility or due to a mentally retarded child with otherwise abnormal karyotype. Here derivative chromosomes were studied by fluorescence in situ hybridization applying probes D15Z1 (specific for 15p11.2) and D22Z4 (specific for $22 \mathrm{p} 11.2$ ). As there are no DNA-sequences available for 13p11.2, 14p11.2 and 21p11.2 these regions could not be tested. Results: D15Z1 sequences were identified in 1 out of 12 derivatives $\operatorname{der}(\mathrm{A}) \mathrm{t}(\mathrm{A}$; acro). D22Z1 could not be detected in any of the 11 remainder derivatives. However, only 3 of the $12 \operatorname{der}(\mathrm{A}) \mathrm{t}(\mathrm{A}$;acro) had acro-ps large enough to potentially comprise sub-band p11.2. Conclusion: In contrast to $\operatorname{der}(\mathrm{Y}) \mathrm{t}(\mathrm{Y} ; \mathrm{acro})(\mathrm{q} 12 ; \mathrm{p} 1$ ?1.2), where in at least $65 \%$ of the cases the acro-p part contains D15Z1 sequences, here it could be shown that in $\operatorname{der}(\mathrm{A}) \mathrm{t}(\mathrm{A} ; \mathrm{acro}) 15 \mathrm{p}$ involvement can be substantiated much less frequently. Also, in none of the two groups D22Z4-sequences were detected in acro-p-parts yet. Besides, breakpoint of acro-pparts in $\operatorname{der}(\mathrm{A}) \mathrm{t}(\mathrm{A}$; acro) seem to be in $\sim 75 \%$ of the cases distal from p11.2.
\end{abstract}

Keywords: acrocentric short arms (acro-ps); chromosomal heteromorphisms (CHMs); D15Z1 (specific for 15p11.2); D22Z4 (specific for 22p11.2) 
Acknowledgments. Clinical cases were provided by Dr. Gödde (Recklinghausen, Germany), Dr. Hehr (Regensburg, Germany), Dr. Hentze (Heidelberg, Germany), Dr. Kläs (Mannheim, Germany), Dr. Lemmens (Aachen, Germany), Drs. Wagner and Stibbe (Hannover, Germany), Dr. Manolakis (Athens, Greece). The probe D22Z4 was kindly provided by Prof. Mariano Rocchi, Bari, Italy.

For citation: Abdulazeez M, Kankel S, Liehr T. About the origin of the acrocentric part of non-acrocentric satellited chromosomes in humans. Research Results in Biomedicine. 2021;7(3):215-219. DOI: 10.18413/2658-6533-2021-7-3-0-1

Introduction. Chromosomal heteromorphisms (CHMs) are considered as cytogenetically detectable gross chromosomal aberrations from the norm, which nonetheless do not lead to any instantaneous clinical consequences. Such changes include euchromatic variants $(\mathrm{EV})$ [1] as well as variations in size and location of heterochromatic DNAstretches [2]. They can be passed through generations and rarely their new formation has been documented [3].

Typical CHMs, being visible in practically each human karyogram, are sizevariations of the acrocentric short arms (acrops), i.e. in the overall ten p-arms of chromosomes 13, 14, 15, 21 and 22. In the "International System for Human Cytogenomic Nomenclature" (ISCN, 2020) it is recommended not mentioning them in genetic reports [4]. Acro-ps typically carry a nucleolus organizing region (NOR) in sub-band p12 with $~ 40$ copies, making up a total of $300-400$ copies per cell [5].

A specific form of CHM involving acro-ps is the presence of an additional, eleventh acro-p being attached at the very tip of another A-chromosome (= in human the chromosomes 1-22 and $\mathrm{X}$ or $\mathrm{Y}$ ). In case if a normal carrier, (almost) no euchromatic material is lost at the telomeric end of the affected A-chromosome, which can be described as $\operatorname{der}(\mathrm{A}) \mathrm{t}(\mathrm{A} ; \mathrm{acro})($ pter or qter;p1?1.2) or nonacrocentric satellited chromosomes. Such derivative chromosomes are only found unexpectedly in infertile diagnostics or parental studies in an otherwise affected child [6]. The most frequently observed $\operatorname{der}(\mathrm{A}) \mathrm{t}(\mathrm{A}$; acro $)$ is the $\operatorname{der}(\mathrm{Y}) \mathrm{t}(\mathrm{Y} ; \mathrm{acro})(\mathrm{q} 12 ; \mathrm{p} 1$ ?1.2); therefor a recent study revealed that at least $65 \%$ those derivatives are indeed a $\operatorname{der}(\mathrm{Y}) \mathrm{t}(\mathrm{Y} ; 15)(\mathrm{q} 12 ; \mathrm{p} 11.2)$ [7].

Accordingly, here we studied 11 healthy carriers of one (10 cases) or two (1 case) $\operatorname{der}(\mathrm{A}) \mathrm{t}(\mathrm{A} ; \mathrm{acro})(\mathrm{pter}$ or qter;p1 ?1.2) to determine the frequency of chromosome $15 p$ and $22 p$ in such rearrangements. Chromosomes 15 and 22 were chosen, as probes are available for $15 \mathrm{p} 11.2$ and $22 \mathrm{p} 11.2$, and not for $13 \mathrm{p} 11.2$, $14 \mathrm{p} 11.2$ or $21 \mathrm{p} 11.2$.

Materials and Methods. Chromosomal preparations were derived from PHAstimulated, cultivated lymphocytes of seven individuals with different indications as listed in Table 1. Karyotyping (= GTG-banding) and FISH were done according to standard procedures [8]. For the latter the following probes were applied: 15p11.2 (D15Z1) (Abbott/Vysis, Wiesbaden, Germany), 22p11.2 (D22Z4) [9], a probe specific for all acrocentric short arms (acro-p = midi54 - microdissection derived probe [10]), whole chromosome painting (wcp) probes $1,4,6,13,18$, 20, 22, X and Y [10]. Four- to five-colorFISH was done as shown in Fig. 1. Probe D15Z1 was labeled in SpectrumGreen, acro-p in Cyanine 5, D22Z4 in SpectrumOrange, wcp probes in diethylaminocoumarine and in case 10 the wcp probe for Y-chromosome in TexasRed. 
Table 1

Patients involved in the study and results of molecular cytogenetics

\begin{tabular}{|c|c|c|c|c|c|}
\hline $\begin{array}{c}\text { Case } \\
\text { number }\end{array}$ & Indication & Derivative chromosome & D15Z1 & D22Z4 & $\begin{array}{c}\text { Length of normal } \\
\text { acro-p-arm [\%] }\end{array}$ \\
\hline 1 & infertile & $\operatorname{der}(1) \mathrm{t}(1 ; \mathrm{acro})(\mathrm{p} 36.33 ; \mathrm{p} 1 ? 1.2)$ & + & - & $>65$ \\
\hline 2 & infertile & $\operatorname{der}(4) \mathrm{t}(4 ; \mathrm{acro})(\mathrm{q} 35.2 ; \mathrm{p} 1 ? 1.2)$ & - & - & $<65$ \\
\hline 3 & infertile (familial) & $\operatorname{der}(4) \mathrm{t}(4 ; \mathrm{acro})(\mathrm{q} 35.2 ; \mathrm{p} 1 ? 1.2)$ & - & - & $<65$ \\
\hline 4 & infertile & $\operatorname{der}(6) \mathrm{t}(6 ; \mathrm{acro})(\mathrm{q} 27 ; \mathrm{p} 1 ? 1.2)$ & - & - & $<65$ \\
\hline 5 & infertile & $\operatorname{der}(13) \mathrm{t}(13 ; \mathrm{acro})(\mathrm{q} 34 ; \mathrm{p} 1 ? 1.2)$ & - & - & $<65$ \\
\hline 6 & infertile & $\operatorname{der}(18) \mathrm{t}(18 ; \mathrm{acro})(\mathrm{qter} ; \mathrm{p} 1 ? 1.2)$ & - & - & $<65$ \\
\hline 7 & infertile & $\operatorname{der}(20) \mathrm{t}(20 ; \mathrm{acro})(\mathrm{p} 13 ; \mathrm{p} 11 . ? 2)$ & - & - & $<$ \\
\hline 8 & infertile & $\operatorname{der}(20) \mathrm{t}(20 ; \mathrm{acro})(\mathrm{p} 13 ; \mathrm{p} 11 . ? 2)$ & - & - & $<65$ \\
\hline 9 & infertile & $\operatorname{der}(22) \mathrm{t}(22 ; \mathrm{acro})(\mathrm{q} 13.33 ; \mathrm{p} 1 ? 1.2)$ & - & - & $<65$ \\
\hline $10 \mathrm{a}$ & $\begin{array}{c}\text { parental test due to } \\
\text { mentally impaired male } \\
\text { child (familial) }\end{array}$ & $\begin{array}{c}\operatorname{der}(\mathrm{X}) \mathrm{t}(\mathrm{X} ; \mathrm{acro})(\mathrm{q} 28 ; \mathrm{p} 1 ? 1.2), \\
\mathrm{der}(\mathrm{Y}) \mathrm{t}(\mathrm{Y} ; \mathrm{acro})(\mathrm{q} 12 ; \mathrm{p} 1 ? 1.2)\end{array}$ & - & - & $<65$ \\
\hline 11 & $\begin{array}{c}\text { parental test due to } \\
\text { mentally impaired } \\
\text { child (familial) }\end{array}$ & $\operatorname{der}(\mathrm{X}) \mathrm{t}(\mathrm{X} ; \mathrm{acro})(\mathrm{q} 28 ; \mathrm{p} 1 ? 1.2)$ & - & - & $>65$ \\
\hline
\end{tabular}

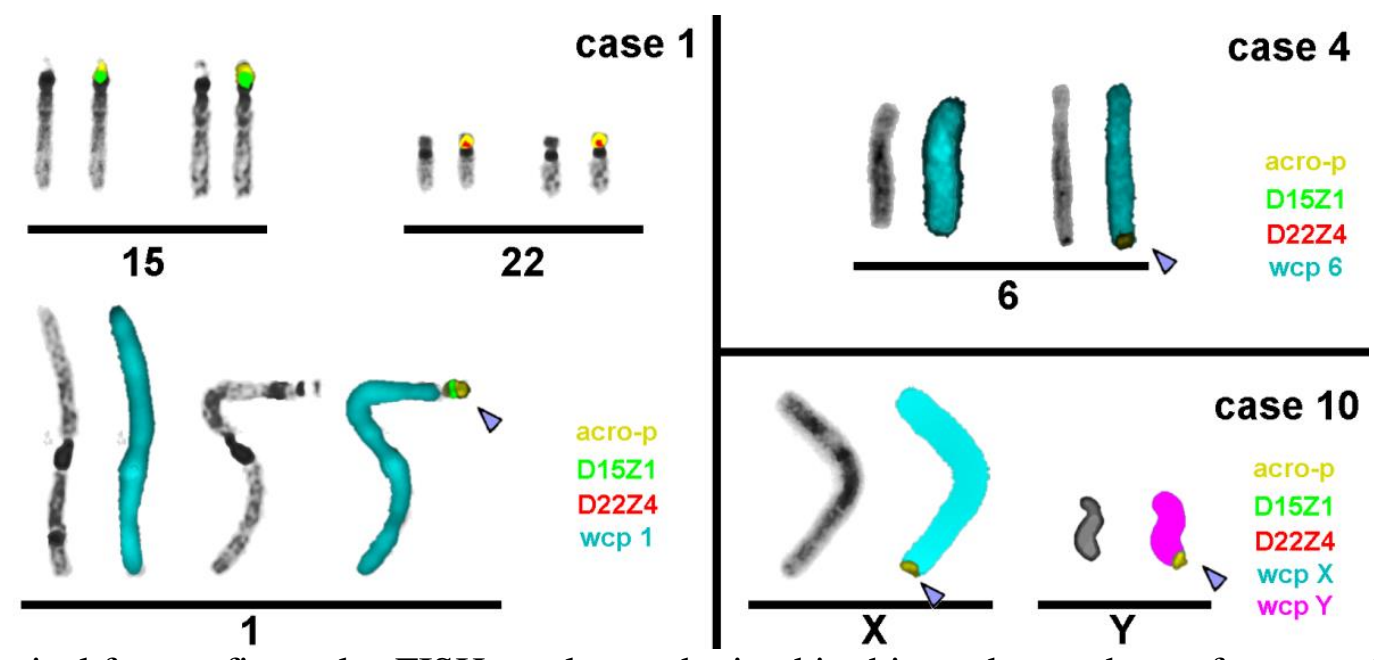

Fig. 1. Typical four to five color FISH results as obtained in this study are shown for cases 1,4 and 10. The used probes and the color-code is given per each of the three figure parts; the derivatives $\operatorname{der}(\mathrm{A}) \mathrm{t}(\mathrm{A} ; \mathrm{acro})$ (pter or qter;p1 ?1.2) of interest are highlighted with arrowheads. For case 1 the typical pattern on the normal chromosomes 15 and 22 is shown together with the result for the chromosomes of interest, here chromosome $1 . A \operatorname{der}(1) \mathrm{t}(1 ; 15)(\mathrm{p} 36.33 ; \mathrm{p} 11.2)$ could be characterized here. For cases 4 and 10 only the chromosome-pairs of interest are shown. In case 4 a very weak signal was observable at the der(6), obviously being a der(6)t(6;acro)(q27;p12 13). In case 10 two $\operatorname{der}(\mathrm{A}) \mathrm{t}(\mathrm{A} ; \mathrm{acro})$ were present and they could be characterized as $\operatorname{der}(\mathrm{X}) \mathrm{t}(\mathrm{X} ; \mathrm{acro})(\mathrm{q} 28 ; \mathrm{p} 12 \sim 13)$ and $\operatorname{der}(\mathrm{Y}) \mathrm{t}(\mathrm{Y} ; \mathrm{acro})(\mathrm{q} 12 ; \mathrm{p} 12 \sim 13)$

\section{Data analyses}

The average length of acrocentric short arms was determined for 5 metaphases per case and compared to the average length of acro-p in der(A;acro). According to Fig. 2 it was estimated that acro-p in $\operatorname{der}(\mathrm{A} ; \mathrm{acro}) \mathrm{com}-$ prises p11.2 parts if it is larger than $65 \%$ of an average p-arm. 


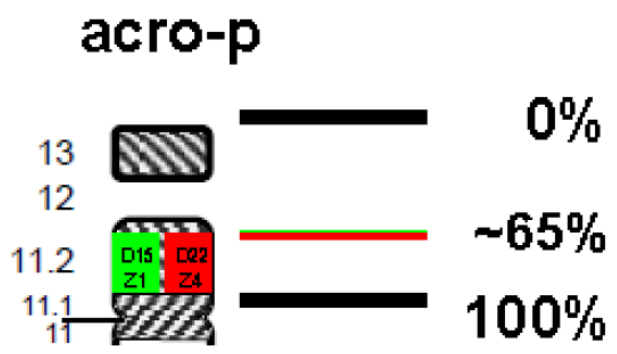

Fig. 2. A scheme for an acrocentric short arm (acro-p) is provided. The location of sequences D15Z1 or D22Z4 in chromosome 15 or 22 are highlighted.as described in Material and Method part it was determined that both sequences can only be expected to be present on a $\operatorname{der}(\mathrm{A}) \mathrm{t}(\mathrm{A} ; \mathrm{acro})$ if it comprises $>65 \%$ of the length of a normal acro-p arm.

\section{Ethics Statement}

The patients were recruited and studied in frame of routine clinical genetics diagnostics.

Results. In 11 cases with overall 12 derivatives only in case $1 \operatorname{der}(\mathrm{A}$; acro) comprised material derived from a short arm of chromosome 15 . Thus, there a $\operatorname{der}(1) t(1 ; 15)(\mathrm{p} 36.33 ; \mathrm{p} 11.1)$ could be characterized. In none of the remained 11 der(A;acro) D15Z1 or D22Z4 material could be detected.

Thus, the cases were further analyzed for the length of the acro-p part on the $\operatorname{der}(\mathrm{A} ; \mathrm{acro})$ compared to the other acro-ps within the same case. According to the evaluation scheme, that sub-band p11.2 can only be comprised in der acro-p arm if it is larger than $65 \%$, there remained only $3 / 12 \operatorname{der}(\mathrm{A}$;acro) being large enough to expect a FISH-result (cases 1, 9 and 11). Accordingly, in all those cases the karyotypes have to been revised to $\operatorname{der}(\mathrm{A}) \mathrm{t}(\mathrm{A} ; \mathrm{acro})($ pter or qter;p12 13).

Discussion. CHMs are clearly understudied. Just recently we could show that at least $65 \%$ of $\operatorname{der}(\mathrm{Y}) \mathrm{t}(\mathrm{Y} ; \mathrm{acro})(\mathrm{q} 12 ; \mathrm{p} 1$ 1.2) can indeed be described as $\operatorname{der}(\mathrm{Y}) \mathrm{t}(\mathrm{Y} ; 15)(\mathrm{q} 12 ; \mathrm{p} 11.2)$ [7]. Corresponding data for other rare cases with $\operatorname{der}(\mathrm{A}) \mathrm{t}(\mathrm{A} ; \mathrm{acro})$ were not available yet.

Here it could be shown that most of $\operatorname{der}(\mathrm{A}) \mathrm{t}(\mathrm{A} ; \mathrm{acro})$ have the acrocentric breakpoint rather in $\mathrm{p} 12 \sim 13$ than in p11.1 11.2. This hampers also for future studies their clear attribution to a chromosomal origin, as also e.g. tried without much success be other by $\alpha$ - or $\beta$-satellite probes [6]. As in 3 out of $12 \operatorname{der}(\mathrm{A}) \mathrm{t}(\mathrm{A} ; \mathrm{acro})$ the acrocentric breakpoint seemed to be in p11.2 or even p11.1, it may be deduced carefully that other than for $\operatorname{der}(\mathrm{Y}) \mathrm{t}(\mathrm{Y}$; acro) cases D15Z1 is less often involved in $\operatorname{der}(\mathrm{A}) \mathrm{t}(\mathrm{A} ; \mathrm{acro})$.

It is well known that non-deleterious mutations / aberrations in the Y-chromosome can be by far easier spread in a population than such on other human chromosomes. Thus, it is logical to find $\operatorname{der}(\mathrm{Y}) \mathrm{t}(\mathrm{Y}$; acro $)$ more often than all other variants of $\operatorname{der}(\mathrm{A}) \mathrm{t}(\mathrm{A} ; \mathrm{acro})$. Also, for the latter variant even a founder effect is described for Canadian population [11].

For $\operatorname{der}(\mathrm{A}) \mathrm{t}(\mathrm{A} ; \mathrm{acro})$ no founder effects were reported yet, still in the present study 3 of 11 cases (cases 3,10 and 11) were familial (Tab.1), as were also other described in literature $[2,6]$.

Conclusion. In conclusion, together with our recent previous work [7] the enigma of origin of the acrocentric part of nonacrocentric satellited chromosomes in humans could be a bit more enlighted. While in $\operatorname{der}(\mathrm{Y}) \mathrm{t}(\mathrm{Y} ; \mathrm{acro})(\mathrm{q} 12 ; \mathrm{p} 1$ ?1.2) in at least $65 \%$ of the cases the acro-p part contains D15Z1 sequences, here it could be shown that in $\operatorname{der}(\mathrm{A}) \mathrm{t}(\mathrm{A} ; \mathrm{acro})$ the $15 \mathrm{p}$ involvement can be substantiated much less frequently. Also, in none of the two groups D22Z4-sequences were detected in acro-p-parts yet. Besides, breakpoint of acro-p-parts in $\operatorname{der}(\mathrm{A}) \mathrm{t}(\mathrm{A}$; acro) seem to be in $\sim 75 \%$ of the cases distal from p11.2. 


\section{Author Contributions}

$T L$ developed the idea for the study; MA and SK did the FISH-studies and the overall data interpretation; all authors agreed on final draft.

\section{Financial support}

No financial support has been provided for this work.

\section{Conflict of interests}

The authors have no conflict of interest to declare.

\section{References}

1. Liehr T. Benign \& Pathological Chromosomal Imbalances, Microscopic and Submicroscopic Copy Number Variations (CNVs) in Genetics and Counseling. Academic Press: New York, USA; 2014.

2. Liehr T. Cases with heteromorphisms. 2021 [cited 2021 July 2]. Available from: http://cs-tl.de/DB/CA/HCM/0-Start.html

3. Kosyakova N, Grigorian A, Liehr T, et al. Heteromorphic variants of chromosome 9. Molecular Cytogenetics. 2013;6(1):14. DOI: https://doi.org/10.1186/1755-8166-6-14

4. McGowan-Jordan J, Hastings RJ, Moore S. ISCN 2020, An International System for Human Cytogenomic Nomenclature. Karger, Zürich, Switzerland; 2020

5. Wellauer PK, Dawid IB. Isolation and sequence organization of human ribosomal DNA. Journal of Molecular Biology. 1979;128(3):289303. DOI: https://doi.org/10.1016/00222836(79)90089-5

6. Redaelli S, Conconi D, Villa N, et al. Instability of short arm of acrocentric chromosomes: Lesson from non-acrocentric satellited chromosomes. Report of 24 unrelated cases. International Journal of Molecular Sciences. 2020;21(10):3431. DOI: https://doi.org/10.3390/ijms21103431
7. Fuchs S, Lisfeld J, Kankel S, et al. The acrocentric part of $\operatorname{der}(\mathrm{Y}) \mathrm{t}(\mathrm{Y} ; \mathrm{acro})(\mathrm{q} 12 ; \mathrm{p} 1 ? 2)$ contains D15Z1 sequences in the majority of cases. Human Genome Variation. 2021, in press.

8. Liehr T. Fluorescence in situ Hybridization (FISH) - Application Guide, 2nd ed., Springer: Berlin, Germany; 2017.

9. Shiels C, Coutelle C, Huxley C. Contiguous arrays of satellites 1,3 , and beta form a $1.5-\mathrm{Mb}$ domain on chromosome $22 \mathrm{p}$. Genomics. 1997;44(1):35-44.

DOI: https://doi.org/10.1006/geno.1997.4817

10. Mrasek K, Heller A, Rubtsov N, et al. Detailed Hylobates lar karyotype defined by $25-$ color FISH and multicolor banding. International Journal of Molecular Medicine. 2003;12(2):139146. DOI: https://doi.org/10.3892/ijmm.12.2.139

11.Genest P. An eleven-generation satellited Y chromosome. The Lancet. 1972;1(7759):1073. DOI: https://doi.org/10.1016/s0140-6736(72)91258-5

Received 2 July 2021

Revised 3 August 2021

Accepted 12 August 2021

\section{Information about the authors}

Mohammed Abdulazeez, Bachelor student, Institute of Human Genetics of the Jena University Hospital, Friedrich Schiller University Jena, Jena, Germany, E-mail: mohammed.abdulazeez@unijena.de, ORCID: https://orcid.org/0000-00022651-6940.

Stefanie Kankel, Medical Technical Assistant, Institute of Human Genetics of the Jena University Hospital, Friedrich Schiller University Jena, Jena, Germany, E-mail: Stefanie.Kankel@med.uni-jena.de, ORCID: https://orcid.org/0000-0003-1042-5267.

Thomas Liehr, PhD, PD, Head of Molecular Cytogenetics Laboratory, Institute of Human Genetics of the Jena University Hospital, Friedrich Schiller University Jena, Jena, Germany, E-mail: Thomas.Liehr@med.uni-jena.de, ORCID: https://orcid.org/0000-0003-1672-3054. 